Research article

\title{
Association of characters and selection parameters for high tuber yield in Potato (Solanum tuberosum L.)
}

\author{
Archana Tiwari, Archana Mishra*, Vishal Saxena, Swati Saxena and \\ Amit Prakash Raghuvanshi
}

\author{
Department of Botany, D. A-V. College Kanpur-208013, Uttar Pradesh, India \\ *Corresponding Author: archnamishra123.am@gmail.com \\ [Accepted: 14 April 2020]
}

\begin{abstract}
The present study was undertaken on twenty genotypes for the information of the nature of the correlation among the different yield parameters. Genotypic correlation was higher than phenotypic correlation in all the characters. Yield showed significant positively correlated with number of sprouts/plant, height of plant, diameter of shoot, length of leaf, in both genotypic and phenotypic levels during the experiments.
\end{abstract}

Keywords: Genetic advance - Growth prameter - Crop productivity - Crop duration.

[Cite as: Tiwari A, Mishra A, Saxena V, Saxena S \& Raghuvanshi AP (2020) Association of character and selection parameters for high tuber yield in Potato (Solanum tuberosum L.). Tropical Plant Research 7(1): 205208]

\section{INTRODUCTION}

Potato (Solanum tuberosum L.) is one of the most versatile vegetable crops, that furnishes appreciable amount of vitamin B and vitamin C as well as some minerals, which is capable of giving highly in return as yields in short span of time. Good quality Potato is the most important aspect in breeding program grade yield in potato, a complex character has high quality content and also associated with many interrelated components. Tuber production is improved by using proper genotypes and environment under different regions. Time of showing and planting methods is also very important for high yield (Nanda 2009). The major potato growing states in the country are Uttar Pradesh, West Bengal, Bihar, Assam, Madhya Pradesh, Punjab, Gujrat and Himanchal. It is cultivated in rabi season where the crop grown is 1.23 Lakh hectares of area with 37.98 lakh metric tones production and average yield of $31.0 \mathrm{qt} \mathrm{ha}^{-1}$ (Anonymous 2017). Keeping to the view the present study was carried out in correlation of potato in different growth parameters including yield.

\section{MATERIAL AND METHODS}

The material consisted of 20 genotype culture/strain of potato used in present study. The material was grown in a randomized block design with three replication at the experimental plot of the department of horticulture Chandrra Shekhar Azad University of Agriculture and Technology, Kanpur. Tubers were planted in rows, the spacing between row to row was $60 \mathrm{~cm}$ and in plant to plant $20 \mathrm{~cm}$. Ten plants from each genotypes were selected for recording data on then quantitative characters of potato yield attributing character for the estimate of correlation method was suggested by Aljibouri et al. (1958).

\section{RESULTS AND DISCUSSION}

The analysis of the variance for the characters revealed that the twenty varieties taken for this study highly significant differences among selected genotypes. The maximum heritability were recorded in yield $\mathrm{qt} \mathrm{ha}^{-1}$ of plant 99,750, height of plant 98,406. All the quantitative characters in potato revealed a considerable variation in plant material of potato. Morphological and genetic variability which gave important information of all the treatment. It was found that variable has mostly positive relationships. High heritability and genetic advance (GA) in yield $\mathrm{qt} \mathrm{ha}^{-1}$ indicated that there was influence of additive genetic variance. Sprouting of potato tuber was positivelycorrelated with the diameter of the shoot $(0.18672)$ length of leaf $(0.10834)$, width of leaf (0.18730), number of days required for crop maturity (0.01104) and yield in qt ha ${ }^{-1}(0.06955)$ in the case of phenotypic correlation study (Table 1). The present observations were in accordance with the Pandita \& Sidhu 
(1980) and Gerg \& Bhutani (1991). Number of sprouts/plant was positively correlated with all the characters of potato accepted the number of days required for sprouting in the phenotypic level. Width of leaf, number of days for crop maturity and yield of potato crop also showed positive correlation.

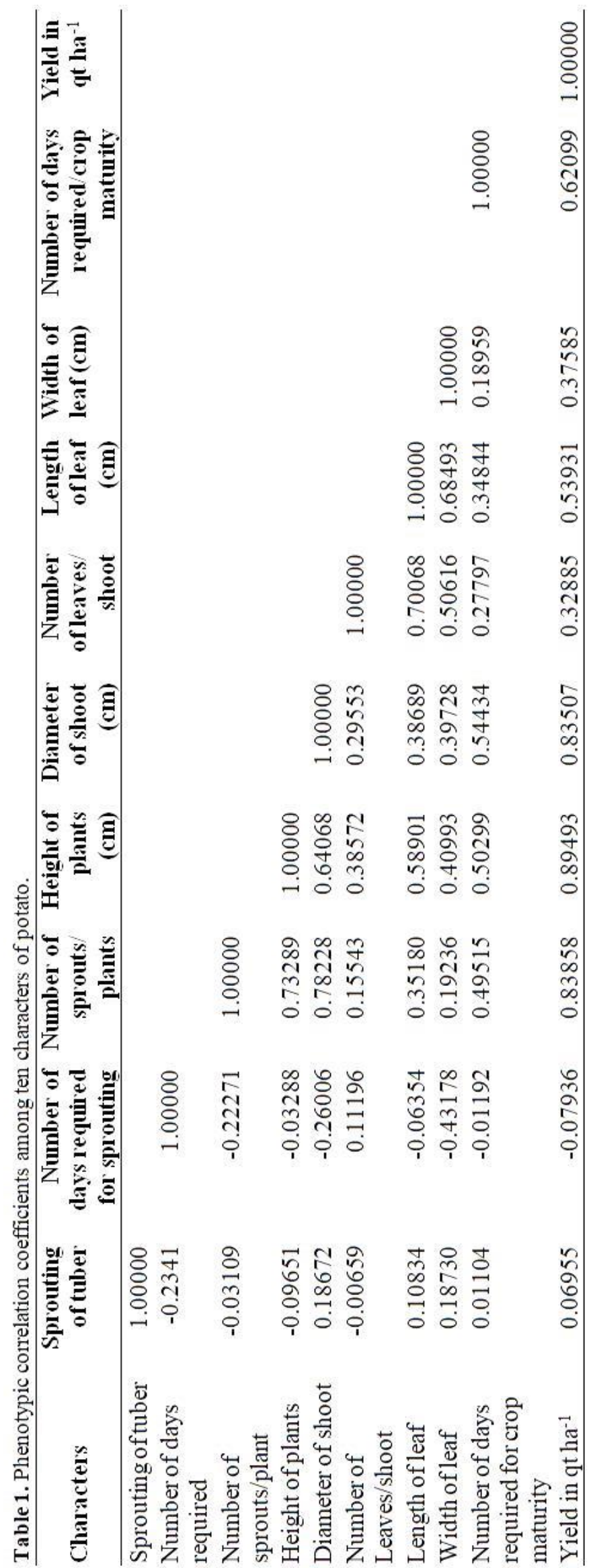




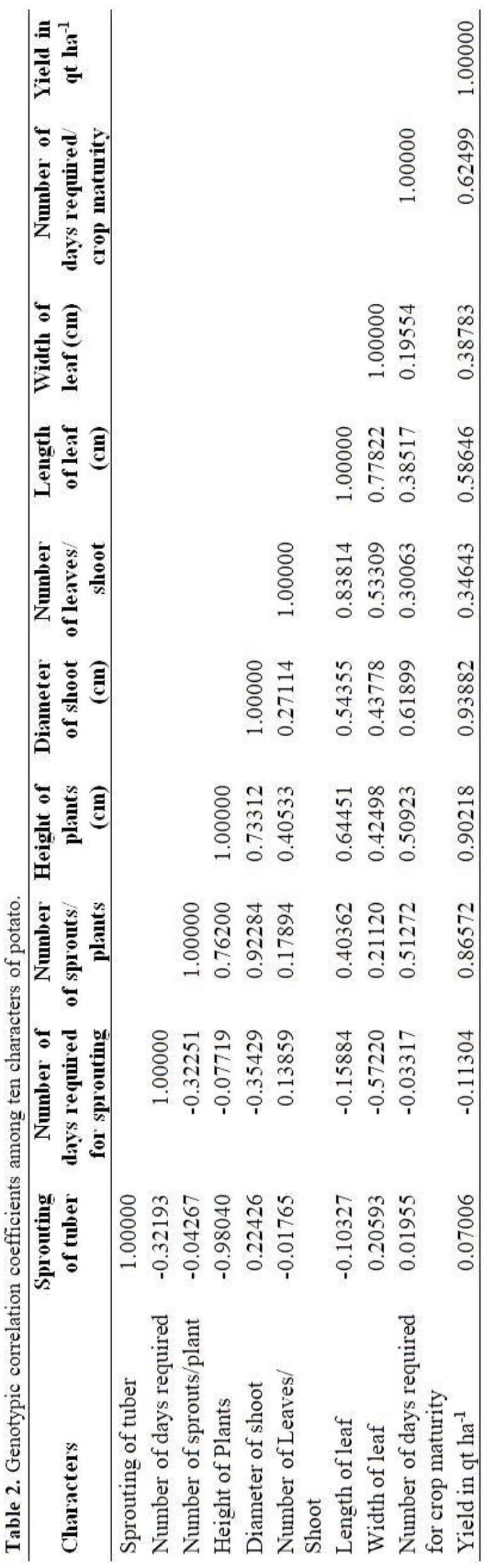


In genotypic correlation coefficient, the sprouting of tuber was positively correlated with the diameter of shoot (0.22426), length of leaf (0.10327), width of the leaf (0.20593), number of days required for crop maturity (0.01955) (Table 2). The Number of sprouts/plant shown significantly positive correlated with height of plant, diameter of shoot, length of leaf number of days required for sprouting and yield of crop. There finding are in close conformity with those of Mishra et al. (1994). The results of present study are in agreement with the different findings for number of stem per plant, plant tubers weight, total tuber yield via no. of tubers per plant (Shashi 2011, Patel et al. 2018). In general the value of genotypic correlation slightly higher than their phenotypic counterparts.

\section{CONCLUSION}

The research revealed a wide range of variability for all traits. Based on the present investigation it may be concluded that crop productivity, sprouts/plant, crop duration/maturity days were the most important for quality tuber yield. The maximum phenotypic and genotypic coefficient of variation was noted for number of sprout/plant weight of tuber/plant and width of leaf. Therefore, emphasis on these characters in selection and importance of "A" grade yield in potato breeding may be rewarding and effective.

\section{REFERENCES}

Aljibouri RA; Miller RA \& Robinson HF (1985) Genotypic environmental variation and covariation in an upland cotton, cross of interspecfic of origin. Journal of Agrobiology 50: 533-536.

Anonymous (2017) District wise area, production and yield per hectare of important food and non-food crops in Gujrat Directorate state of agriculture, Gujrat state KrishiBhawan, Chandigrah.

Garg LP \& Bhutani RD (1991) Studies on correlation and path analysis in potato. Haryana Journal of Horticultural Sciences 20(2-3): 255-260.

Mishra A, Prasad A \& Singh PD (1994) Heritability and correlation studies in potato (Solanum tuberosum). Form Science Journal 6(9): 67-71.

Nanda HC(2009) Suitable potato hybrids and is cultivation in Chhattisgarh. In: National Symposium achieving millennium development and prospects. pp. 24-27.

Pandita ML \& Sidhu AS (1980) Correlation and path analysis of some economic characters in potato. Haryana Journal of Horticultural Sciences 9(1-2): 62-65.

Patel RA, Bhavani RT, Patel DK \& Patel JR (2018) Character Association and Path coefficient studies for yield component in Potato (Solanum tuberosum). International Journal of Current Microbiology and Applied Sciences 7(8): 1942-1950.

Shashi K (2011) Variability and association for morphological and biochemical traits in potato. Indian Journal of Genetics 71(1): 74-77. 